\title{
СУММАРНОЕ СОДЕРЖАНИЕ АНТИОКСИДАНТОВ В ЗЕРНЕ ЯЧМЕНЯ, ВЫРАЩЕННОГО В УСЛОВИЯХ РЕСПУБЛИК ХАКАСИЯ И ТЫВА
}

\author{
V.I. Polonsky, A.V. Sumina, T.M. Shaldaeva \\ THE TOTAL CONTENT OF ANTIOXIDANTS \\ IN BARLEY GRAIN GROWN IN THE CONDITIONS OF THE REPUBLICS OF KHAKASSIA AND TYVA
}

Полонский Вадим Игоревич - д-р биол. наук, проф. каф. ландшафтной архитектуры, ботаники, агроэкологии Красноярского государственного аграрного университета, г. Красноярск.

E-mail: vadim.polonskiy@mail.ru

Сумина Алена Владимировна - канд. с.-х. наук, доц. каф. химии и геоэкологии Хакасского государственного университета им. Н.Ф. Катанова, г. Абакан. E-mail: alenasumina@list.ru

Шалдаева Татьяна Михайловна - канд. биол. наук, науч. сотр. Центрального сибирского ботанического сада СО РАН, г. Новосибирск.

E-mail: shaldaeva@yandex.ru

Цель исследования - изучение генотипсредового влияния на суммарное содержание антиоксидантов в зерне ячменя. Исследовали суммарное содержание антиоксидантов (ССА) в зерне 10 образцов ячменя, выращенных в двух различающихся по климатическим условиям географрических пунктах. Один из них расположен на Пий-Хемском госсортучастке (Республика Тыва), другой - на Бейском госсортучастке (Республика Хакасия). В Тыве максимальные дневные температуры были выше, а минимальные ночные ниже, что создавало более контрастную разность суточного хода температуры. Экстракцию зерна проводили двумя методами - с помощью горячей бидистиллированной воды и 70 \% спирта. Уровень ССА измеряли на приборе «Цвет Яуза-01-АА». В качестве образца сравнения использовали галловую кислоту. Показано, что при использовании двух методов экстракции были зарегистрированы практически одинаковые результаты. Установлено, что величина ССА у различных сортов ячменя варьировала от 44 до 88 мг/100 г сухой массы. Максимальный уровень ССА в зерне был характерен для сортов Ача и Уватский, а ми-
Polonsky Vadim Igorevich - Dr. Biol. Sci., Prof., Chair of Landscape Architecture, Botany, Agroecology, Krasnoyarsk State Agrarian University, Krasnoyarsk.

E-mail: vadim.polonskiy@mail.ru

Sumina Alyona Vladimirovna - Cand. Agr. Sci., Assoc. Prof., Chair of Chemistry and Geoecology, N.F. Katanov Khakass State University, Abakan.

E-mail: alenasumina@list.ru

Shaldaeva Tatyana Mikhaylovna - Cand. Biol. Sci., Staff Scientist, Central Siberian Botanical Garden SB RAS, Novosibirsk.

E-mail: shaldaeva@yandex.ru

нимальный - для сортов Биом и Оленек вне зависимости от условий выращивания ячменя. Найдено, что более аридные условия выращивания растений, складывающиеся в Республике Тыва, сопровождаются значительным усилением накопления антиоксидантов в зерне. Показано, что значение ССА в зерне на 67 \% завиcит от фрактора «пункт» и на $24 \%$ от генотипа. На основании полученных результатов заключается возможность выращивания на территории Республики Тыва ячменя с высоким содержанием антиоксидантов в зерне.

Ключевые слова: зерно, ячмень, сорт, антиоксиданты, элюент, бидистиллированная вода, спирт, Республика Тьва, Республика Хакасия.

The research objective was studying a genotypeenvironmental influence on the total content of antioxidants (TCA) in barley grain. The total content of antioxidants (TCA) in the grain of 10 barley samples grown in two different climatic conditions geographical locations was studied. One of them was located in Piy-Khemstate varietal plot (Republic of Tyva), the other in Bey state varietal plot (Republic of Khakasia). 
In Tyva the maximum daytime temperatures were higher and the minimum night temperatures were lower, which created a more contrasting difference in the daily course of temperature. Grain extraction was carried out by two methods - using hot bidistilled water and $70 \%$ alcohol. The level of TCA was measured by the device "Tsvet-Yauza-01-AA". Gallic acid was used as a comparison sample. It was shown that almost identical results were registered when using two extraction methods. It was found that the value of TCA in different varieties of barley varied from 44 to $88 \mathrm{mg} / 100 \mathrm{~g}$ dry weight. The maximum level of TCA in the grain was typical for the varieties Acha and Uvatsky, and the minimum for the varieties Biom and Olenek, regardless of the growing conditions of barley. It was found that more arid conditions of growing plants, which are developing in the Republic of Tyva, were accompanied by a significant increase in the accumulation of antioxidants in the grain. It was shown that the value of TCA in the grain is $67 \%$ dependent on the factor "point" and $24 \%$ of the genotype. Based on the results obtained, it is possible to grow barley with a high content of antioxidants in the grain on the territory of the Republic of Tyva.

Keywords: grain, barley, variety, antioxidants, eluent, bidistilled water, alcohol, Republic of Tyva, Republic of Khakasia.

Введение. Химические соединения, которые, останавливая цепные реакции, способствуют удалению свободных радикалов путем самоокисления, относятся к антиоксидантам [1]. Зерновые злаки являются широко распространенными компонентами растительной пищи и корма, поэтому понятен интерес к изучению их антиоксидантных свойств, а также влияния на последние генотипа и условий выращивания растений.

Установлено, что общая антиоксидантная активность зерновых культур обусловлена как внешними факторами (погодные условия, применение удобрений), так и генотипом [2-4]. Показано, что в зерне различных образцов ячменя общее содержание токола, относящегося к антиоксидантам, колебалось от 40 до 82 мкг/г. Всего в 27 образцах авторами было выявлено 64 соединения с антиоксидантной активностью, среди которых 19 фенольных кислот и альдегидов, 9 фрлавоновых гликозидов и 27 антоцианов [5]. В экспериментах с 25 сортами ячменя была найдена пониженная антиоксидантная актив- ность у голозерных генотипов [6]. В другой работе, при изучении содержания токолов, фолиевой кислоты и фенольных кислот в зерне 10 пленчатых и голозерных сортов ячменя, выращенных в одних и тех же условиях, были получены схожие результаты [7].

Ряд авторов пришли к выводу о большем влиянии окружающей среды по сравнению с генотипом на антиоксидантную активность зерна. Этот факт был установлен при изучении 39 сортов овса, выращенных в четырех местах в Китае [8]. На пшенице и ячмене было показано, что высокие температуры и засуха приводили к более значительному биосинтезу каротиноидов в зерне [9], а обильные осадки и пониженные температуры способствовали более высокому содержанию токола у большинства сортов [10]. Известно, что неблагоприятные для роста экологические условия могут увеличивать содержание антиоксидантов в растениях. Окислительный стресс, вызванный накоплением активных фрорм кислорода, вызывает в клетках многочисленные ответные реакции, в том числе антиоксидантных систем, которые, как правило, приводят к увеличению концентрации антиоксидантов в растениях [11].

В настоящее время в России выполнено недостаточно исследований, посвященных определению антиоксидантной активности зерновых культур $[2,3,12]$.

Цель исследования: изучение генотипсредового влияния на суммарное содержание антиоксидантов в зерне ячменя.

Объект и методы исследования. Были исследованы образцы, выращенные в двух географических районах, различающихся по климатическим условиям.

В качестве объекта исследования использовали 10 сортов ярового пленчатого ячменя (Hordeum vulgare L.) сибирской селекции, выращенного на территории двух сортоучастков: Бейского (Республика Хакасия) и Пий-Хемского (Республика Тыва). Бейский ГСУ расположен в степной зоне предгорий на обыкновенных и южных черноземах Республики Хакасия. Пий-Хемский ГСУ находится в лесостепной почвенно-климатической зоне Республики Тыва. По климатическим условиям выбранные участки относятся к зоне рискованного земледелия с резко континентальным климатом, что не всегда позволяет получать стабильные и высокие урожаи. Существенные колебания тем- 
пературы отмечаются на территории Тувы, где годовые составляют $70-80{ }^{\circ} \mathrm{C}$, а суточные - от 20 до $30{ }^{\circ} \mathrm{C}$. При этом если значение агроклиматического ресурса России принять за 1, то на территории республики оно составляет вдвое меньшую величину $-0,46-0,48$.

Растения ячменя выращивали в течение 2019 г. по паровому предшественнику. Семенной материал был предоставлен сотрудниками указанных ГСУ.

Определение суммарного содержания антиоксидантов (ССА) в образцах зерна ячменя осуществляли в следующей последовательности: вначале получали водный или водноспиртовой экстракт из зерна, производили его фильтрацию, а затем измеряли суммарное содержание антиоксидантов в расчете на сухую биомассу с помощью прибора «Цвет Яуза-01-АА» $[13,14]$, регистрируя величину электрического тока, возникающего при окислении исследуемого вещества (или смеси веществ) на поверхности рабочего электрода при постоянном потенциале 1,3 В. Предварительно изучали зависимость электрического сигнала образца сравне- ния (галловой кислоты) от его концентрации. С помощью построенной градуировочной кривой сравнивали сигналы от исследуемого экстракта с сигналами галловой кислоты. Повторность измерения трехкратная.

Статистическая обработка результатов была выполнена с помощью программы обработки данных полевого опыта FieldExpert vl.3 Pro и MicrosoftExcel 2003 [15].

Результаты исследования. В таблице 1 представлена информация о показателях суточной (дневной и ночной) температуры по месяцам вегетационного периода для двух географических пунктов выращивания ячменя (по данным Метеорологического отчета о непосредственных наблюдениях на сортоучастках). Видно, что в Пий-Хемском ГСУ в Тыве по сравнению с Бейским ГСУ в Хакасии максимальные дневные температуры выше, а минимальные ночные ниже, что создает более высокую разность суточного хода температуры. Отметим, что для августа, когда происходит процесс налива зерна, различия в ночных температурах между двумя пунктами доказаны статистически.

Таблица 1

\section{Значения суточной температуры по месяцам в двух пунктах выращивания ячменя}

\begin{tabular}{|l|l|c|c|c|c|}
\hline \multirow{2}{*}{$\begin{array}{c}\text { Пункт } \\
\text { выращивания }\end{array}$} & \multirow{2}{*}{$\begin{array}{c}\text { Суточная } \\
\text { температура }\end{array}$} & \multicolumn{4}{|c|}{ Среднемесячная температура } \\
\cline { 3 - 6 } \multirow{2}{*}{ гсу, } & Май & Июнь & Июль & Август \\
\hline \multirow{3}{*}{ Гакасия } & Максимальная & $15,9 \pm 1,2$ & $22,5 \pm 0,7$ & $23,2 \pm 0,7$ & $23,5 \pm 0,7$ \\
\cline { 2 - 6 } & Минимальная & $2,0 \pm 0,9$ & $9,5 \pm 0,5$ & $12,6 \pm 0,4$ & $11,5 \pm 0,5^{*}$ \\
\cline { 2 - 6 } & Разность & $13,6 \pm 1,2$ & $13,0 \pm 0,8$ & $10,5 \pm 0,8$ & $12,0 \pm 0,8$ \\
\hline & Максимальная & $16,4 \pm 1,1$ & $23,2 \pm 0,9$ & $23,4 \pm 0,7$ & $23,9 \pm 0,8$ \\
\cline { 2 - 6 } & Минимальная & $0,8 \pm 1,1$ & $8,4 \pm 0,6$ & $11,7 \pm 0,3$ & $9,8 \pm 0,5^{*}$ \\
\cline { 2 - 6 } & Разность & $15,3 \pm 1,2$ & $14,8 \pm 1,0$ & $11,5 \pm 0,8$ & $14,0 \pm 0,8$ \\
\hline
\end{tabular}

*Различия в температуре между пунктами существенны по t-критерию при $p \leq 0,05$.

В таблице 2 представлены результаты измерения суммарного содержания антиоксидантов (CСA) в зерне 10 сортов ячменя. Можно видеть существенные различия в величине этого показателя у большинства образцов, выращенных в двух географических пунктах. При этом среднее значение ССА в зерне ячменя, полученного из Пий-Хемского ГСУ, было на 19 \% выше по сравнению с Бейским ГСУ (достоверность различий доказана для спирторастворимых антиоксидантов). Это свидетельствует о заметном влиянии на указанный биохимический показатель условий внешней среды, складывающихся во время налива зерна, по-видимому, температурного режима в августе. Ранее нами на основе полученных результатов измерения ССА в зерне ячменя, выращиваемого в центральной части Красноярского края и Бейском ГСУ (Республика Хакасия), было высказано предположение, что более аридные условия возделывания ячменя способствуют накоплению антиоксидантов в зерне $[16,17]$. 
Суммарное содержание антиоксидантов в зерне 10 сортов ячменя, выращенных

Таблица 2

в различных пунктах, определенное с помощью двух методов экстракции

\begin{tabular}{|l|c|c|c|c|}
\hline \multirow{2}{*}{ Сорт } & \multicolumn{3}{|c|}{ Суммарное содержание антиоксидантов, мг/100 г } \\
\cline { 2 - 5 } & \multicolumn{2}{|c|}{$70 \%$ этиловый спирт } & Горячая бидистиллированная вода \\
\cline { 2 - 5 } & Тыва & Хакасия & Тыва & Хакасия \\
\hline Буян & $60,0 \pm 0,1^{*}$ & $45,7 \pm 0,4^{*}$ & $62,4 \pm 0,9^{*}$ & $49,7 \pm 0,7^{*}$ \\
\hline Красноярский 91 & $71,0 \pm 1,2$ & $70,1 \pm 0,7$ & $76,0 \pm 0,6^{*}$ & $73,5 \pm 0,6^{*}$ \\
\hline Ача & $80,0 \pm 0,2^{*}$ & $76,8 \pm 0,8^{*}$ & $82,1 \pm 0,7$ & $80,2 \pm 0,6$ \\
\hline Биом & $56,0 \pm 0,3$ & $56,0 \pm 0,6$ & $58,4 \pm 0,7$ & $59,0 \pm 1,0$ \\
\hline Емеля & $79,1 \pm 0,2^{*}$ & $58,1 \pm 0,7^{*}$ & $79,2 \pm 0,4^{*}$ & $58,0 \pm 0,3^{*}$ \\
\hline Танай & $70,3 \pm 0,4^{*}$ & $51,0 \pm 0,3^{*}$ & $73,2 \pm 0,3^{*}$ & $52,3 \pm 0,5^{*}$ \\
\hline Такмак & $80,4 \pm 0,5^{*}$ & $49,1 \pm 0,5^{*}$ & $86,1 \pm 0,2^{*}$ & $50,4 \pm 0,8^{*}$ \\
\hline Уватский & $85,3 \pm 0,3^{*}$ & $82,8 \pm 0,3^{*}$ & $88,5 \pm 0,4^{*}$ & $84,0 \pm 0,4^{*}$ \\
\hline Абалак & $63,2 \pm 0,7^{*}$ & $44,0 \pm 0,5^{*}$ & $60,6 \pm 0,6^{*}$ & $46,0 \pm 0,4^{*}$ \\
\hline Оленек & $60,0 \pm 0,3^{*}$ & $56,3 \pm 0,8^{*}$ & $59,3 \pm 0,2$ & $59,0 \pm 0,7$ \\
\hline Среднее по образцам & $70,5 \pm 3,3^{*}$ & $59,0 \pm 4,2^{*}$ & $72,6 \pm 3,7$ & $61,2 \pm 4,2$ \\
\hline $\begin{array}{l}\text { Средний коэффрици- } \\
\text { ент вариации, \% }\end{array}$ & 8,1 & 12,3 & 8,8 & 11,9 \\
\hline
\end{tabular}

*Различия существенны между пунктами выращивания для каждого сорта в пределах используемого метода экстракции по t-критерию при $p \leq 0,05$.

Исключение составили два сорта ячменя Биом и Оленек, у которых был зарегистрирован уровень ССА в зерне, практически не зависящий от места выращивания. Следует подчеркнуть, что поскольку величина ССА у них характеризовалась минимальным среди всех сортов значением, то отмеченная экологическая стабильность по указанному признаку может иметь малое практическое применение.

Как видно из данных таблицы 2, коэфффициент сортовой вариации значений ССА при выращивании ячменя на территории Тывы был незначителен (8,4 \%), а в условиях Хакасии он имел среднее значение (12,1\%). Вероятно, при увеличении степени аридности среды между сортами происходит сглаживание варьирования величины рассматриваемого признака качества зерна.
Полученные результаты демонстрируют различия в уровнях ССА у исследуемых образцов, размах колебаний для обоих географических пунктов и методов экстракции составил двукратную величину: от 44,0 до 88,5 мг/100 г. Этот факт подтверждает наличие эффректа заметного влияния генотипа на указанный биохимический показатель. Максимальные значения ССА были найдены в зерне сортов Ача и Уватский, выращиваемых как в Республике Тыва, так и в Хакасии.

При использовании двух методов экстракции для определения величины ССА в зерне были зарегистрированы практически одинаковые результаты, которые подтвердили полученные нами ранее экспериментальные данные [16-18]. Усредненные значения коэфффициентов корреляции между уровнями ССА, измеренными по- 
сле экстракции водой и экстракции спиртом, составили существенные величины - 0,980 и 0,996 соответственно. При этом отмечена тенденция превышения уровней содержания водорастворимых антиоксидантов в зерне над спирторастворимыми.

C помощью пакета анализа программ Field Expert v1.3 Pro, который служит для статистической обработки данных, методами дисперсионного анализа было установлено, что независимо от элюента уровень ССА в зерне ячменя, выращенного в исследуемых пунктах, в боль- шей степени (67 \%) определялся фактором «пункт» (рис.). На втором месте по степени влияния располагался фактор «генотип», на долю которого пришлось 24 \%. Вклад взаимодействия факторов «пункт $\times$ генотип» в формирование рассматриваемого показателя составил лишь $7 \%$. Исходя из полученных данных, можно заключить, что в использованных в работе территориях выращивания по уровню ССА в зерне фрактор «пункт» имел наиболее существенное значение.

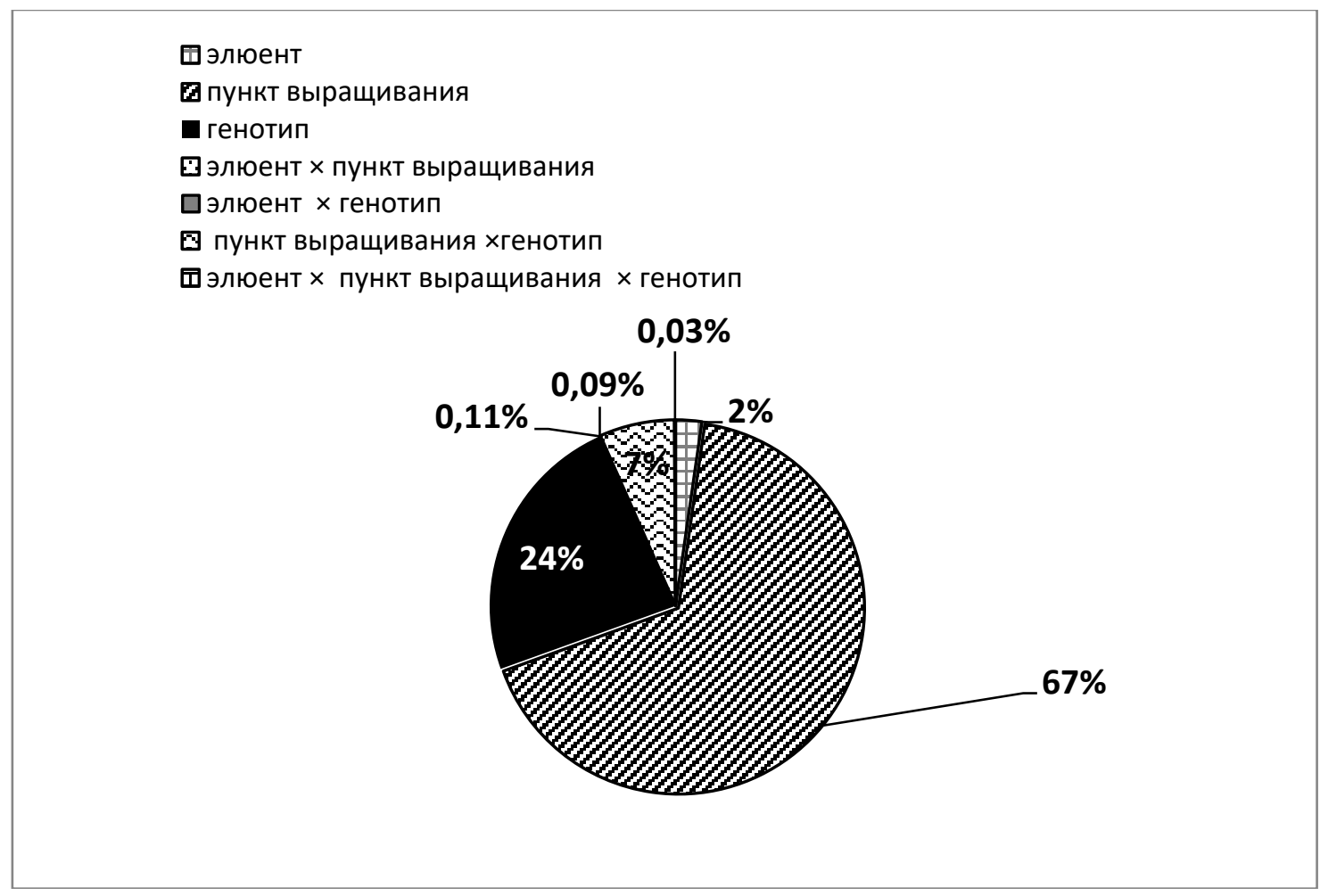

Влияние различных фракторов на показатель ССА в зерне ячменя, выращенного в различных географрических условиях

Учитывая то, что при действии неблагоприятных экологических факторов в процесс защиты растений включаются антиоксиданты, обеспечивая при этом их выживание [18], можно предположить, что зерно с высокими значениями ССА имеет преимущества при выращивании ячменя на территории рискованного земледелия, к каковой в большей степени, чем Хакасия, относится Республика Тыва.

Заключение. Найдено, что более аридные условия выращивания растений, складываю- щиеся в Республике Тыва, сопровождаются усилением накопления антиоксидантов в зерне. Установлено, что для ячменя значение ССА в зерне в основном зависит от фактора «пункт» и в меньшей степени от фактора «генотип». Полученные результаты позволяют заключить возможность возделывания на территории Республики Тыва ячменя с заданным высоким содержанием антиоксидантов в зерне. При этом целесообразно выращивать. 


\section{Литература}

1. Shebis Y., Iluz D., Kinel-Tahan Y. et al. Natural antioxidants: function and sources // Food Nutrition Science. 2013. Vol. 4. P. 643-649.

2. Лоскутов И.Г. Овес (Avena L.). Распространение, систематика, эволюция и селекционная ценность / ГНЦ РФ ВИР. СПб., 2007.

3. Полонский В.И., Сумина А.В., Павлова Е.В. и др. Варьирование суммарного содержания антиоксидантов в зерне овса и ячменя, выращенного в условиях межгорных котловин // Успехи современного естествознания. 2016. № 8. C. 114-119.

4. Mareček V., Mikyška A., Hampel D. et al. ABTS and DPPH methods as a tool for studying antioxidant capacity of spring barley and malt // Journal of Cereal Science. 2017. Vol. 73, № 1. P. 40-45.

5. Martínez M., Motilva M.J., Hazas M-C.L. et al. Phytochemical composition and $\beta$-glucan content of barley genotypes from two different geographic origins for human health food production // Food Chemistry. 2018. Vol. 245. P. 61-70.

6. Do T.D.T., Cozzolino D., Muhlhausler B. et al. Antioxidant capacity and vitamin $\mathrm{E}$ in barley: Effect of genotype and storage // Food Chemistry. 2015. V. 187, № 15. P. 65-74.

7. Andersson A.A.M., Lampi A.M., Nyström L. et al. Phytochemical and Dietary Fiber Components in Barley Varieties in the HEALTHGRAIN Diversity Screen // Journal of Agricultural and Food Chemistry. 2008. V. 56, № 21. P. 9767-9776.

8. Li X.P., Li M.Y., Ling A.J. et al. Effects of genotype and environment on avenanthramides and antioxidant activity of oats grown in northwestern China // Journal of Cereal Science. 2017. V. 73. P. 130-137.

9. Paznocht L., Kotíková Z., Lachman J. et al. Free and esterified carotenoids in pigmented wheat, tritordeum and barley grains // Food Chemistry. 2018. Vol. 240, № 2. P. 670-678.

10. Lachman J., Hejtmánková A., Orsák M. et al. Tocotrienols and tocopherols in colored-grain wheat, tritordeum and barley // Food Chemistry. 2018. Vol. 240, № 2. P. 725-735.
11. Wang Y., Frei M. Stressed food - The impact of abiotic environmental stresses on crop quality // Agriculture, Ecosystems and Environment. 2011. V. 141. P. 271-286.

12. Яшин А.Я., Яшин Я.Н., Федина П.А., Черноусова Н.И. Определение природных антиоксидантов в пищевых злаках и бобовых культурах // Аналитика. 2012. Т. 2, № 1. C. 32-36.

13. Полонский В.И., Сумина А.В., Шалдаева T.M. Содержание антиоксидантов в зерне сибирских сортов овса, выращенного в различных условиях // Вестник КрасГАУ. 2018. № 1. С. 18-24.

14. Федина П.А., Яшин А.Я., Черноусова Н.И. Определение антиоксидантов в продуктах растительного происхождения амперометрическим методом // Химия растительного сырья. 2010. № 2. С. 91-97.

15. Акимова О.И., Акимов Д.Н. Использование статистических методов обработки опытных данных при выполнении студенческих научных работ // Вестник ХГУ. 2016. № 18. C. 76-78.

16. Полонский В.И., Сумина А.В., Шалдаева Т.М. Суммарное содержание природных антиоксидантов в зерне ячменя в различных условиях выращивания // Вестник КрасГАУ. 2017. № 12. C. 21-28.

17. Полонский В.И., Сумина А.В., Шалдаева Т.М. Влияние условий выращивания ячменя на суммарное содержание антиоксидантов в зерне и величину продуктивности // Вестник КрасГАУ. 2019. № 7. С. 24-30.

18. Полонский В.И., Сумина А.В., Шалдаева Т.М. Зависимость суммарного содержания антиоксидантов в зерне ячменя и овса сибирской селекции от условий выращивания // Вестник КрасГАУ. 2016. № 9. С. 72-81.

\section{Literatura}

1. Shebis Y., Iluz D., Kinel-Tahan Y. et al. Natural antioxidants: function and sources // Food Nutrition Science. 2013. Vol. 4. P. 643-649.

2. Loskutov I.G. Oves (Avena L.). Rasprostranenie, sistematika, jevoljucija i selekcionnaja cennost' / GNC RF VIR. SPb., 2007. 
3. Polonskij V.I., Sumina A.V., Pavlova E.V. i dr. Var'irovanie summarnogo soderzhanija antioksidantov $\mathrm{v}$ zerne ovsa i jachmenja, vyrashhennogo $\mathrm{v}$ uslovijah mezhgornyh kotlovin II Uspehi sovremennogo estestvoznanija. 2016. № 8. S. 114-119.

4. Mareček V., Mikyška A., Hampel D. et al. ABTS and DPPH methods as a tool for studying antioxidant capacity of spring barley and malt // Journal of Cereal Science. 2017. Vol. 73, № 1. P. 40-45.

5. Martínez M., Motilva M.J., Hazas M-C.L. et al. Phytochemical composition and $\beta$-glucan content of barley genotypes from two different geographic origins for human health food production // Food Chemistry. 2018. Vol. 245. P. 61-70.

6. Do T.D.T., Cozzolino D., Muhlhausler B. et al. Antioxidant capacity and vitamin $\mathrm{E}$ in barley: Effect of genotype and storage // Food Chemistry. 2015. V. 187, № 15. P. 65-74.

7. Andersson A.A.M., Lampi A.M., Nyström L. et al. Phytochemical and Dietary Fiber Components in Barley Varieties in the HEALTHGRAIN Diversity Screen // Journal of Agricultural and Food Chemistry. 2008. V. 56, № 21. P. 9767-9776.

8. Li X.P., Li M.Y., Ling A.J. et al. Effects of genotype and environment on avenanthramides and antioxidant activity of oats grown in northwestern China // Journal of Cereal Science. 2017. V. 73. P. 130-137.

9. Paznocht L., Kotíková Z., Lachman J. et al. Free and esterified carotenoids in pigmented wheat, tritordeum and barley grains // Food Chemistry. 2018. Vol. 240, № 2. P. 670-678.

10. Lachman J., Hejtmánková A., Orsák M. et al. Tocotrienols and tocopherols in colored-grain wheat, tritordeum and barley // Food Chemistry. 2018. Vol. 240, № 2. P. 725-735.
11. Wang Y., Frei M. Stressed food - The impact of abiotic environmental stresses on crop quality // Agriculture, Ecosystems and Environment. 2011. V. 141. P. 271-286.

12. Jashin A.Ja., Jashin Ja.N., Fedina P.A., Chernousova N.I. Opredelenie prirodnyh antioksidantov $v$ pishhevyh zlakah i bobovyh kul'turah // Analitika. 2012. T. 2, № 1. S. 32-36.

13. Polonskij V.I., Sumina A.V., Shaldaeva T.M. Soderzhanie antioksidantov $v$ zerne sibirskih sortov ovsa, vyrashhennogo $v$ razlichnyh uslovijah // Vestnik KrasGAU. 2018. № 1. S. 18-24.

14. Fedina P.A., Jashin A.Ja., Chernousova N.I. Opredelenie antioksidantov $\mathrm{V}$ produktah rastitel'nogo proishozhdenija amperometricheskim metodom // Himija rastitel'nogo syr'ja. 2010. № 2. S. 91-97.

15. Akimova O.I., Akimov D.N. Ispol'zovanie statisticheskih metodov obrabotki opytnyh dannyh pri vypolnenii studencheskih nauchnyh rabot // Vestnik HGU. 2016. № 18. S. 76-78.

16. Polonskij V.I., Sumina A.V., Shaldaeva T.M. Summarnoe soderzhanie prirodnyh antioksidantov $v$ zerne jachmenja $v$ razlichnyh uslovijah vyrashhivanija // Vestnik KrasGAU. 2017. № 12. S. 21-28.

17. Polonskij V.I., Sumina A.V., Shaldaeva T.M. Vlijanie uslovij vyrashhivanija jachmenja na summarnoe soderzhanie antioksidantov $\mathrm{v}$ zerne i velichinu produktivnosti // Vestnik KrasGAU. 2019. № 7. S. 24-30.

18. Polonskij V.I., Sumina A.V., Shaldaeva T.M. Zavisimost' summarnogo soderzhanija antioksidantov $v$ zerne jachmenja i ovsa sibirskoj selekcii ot uslovij vyrashhivanija // Vestnik KrasGAU. 2016. № 9. S. 72-81. 